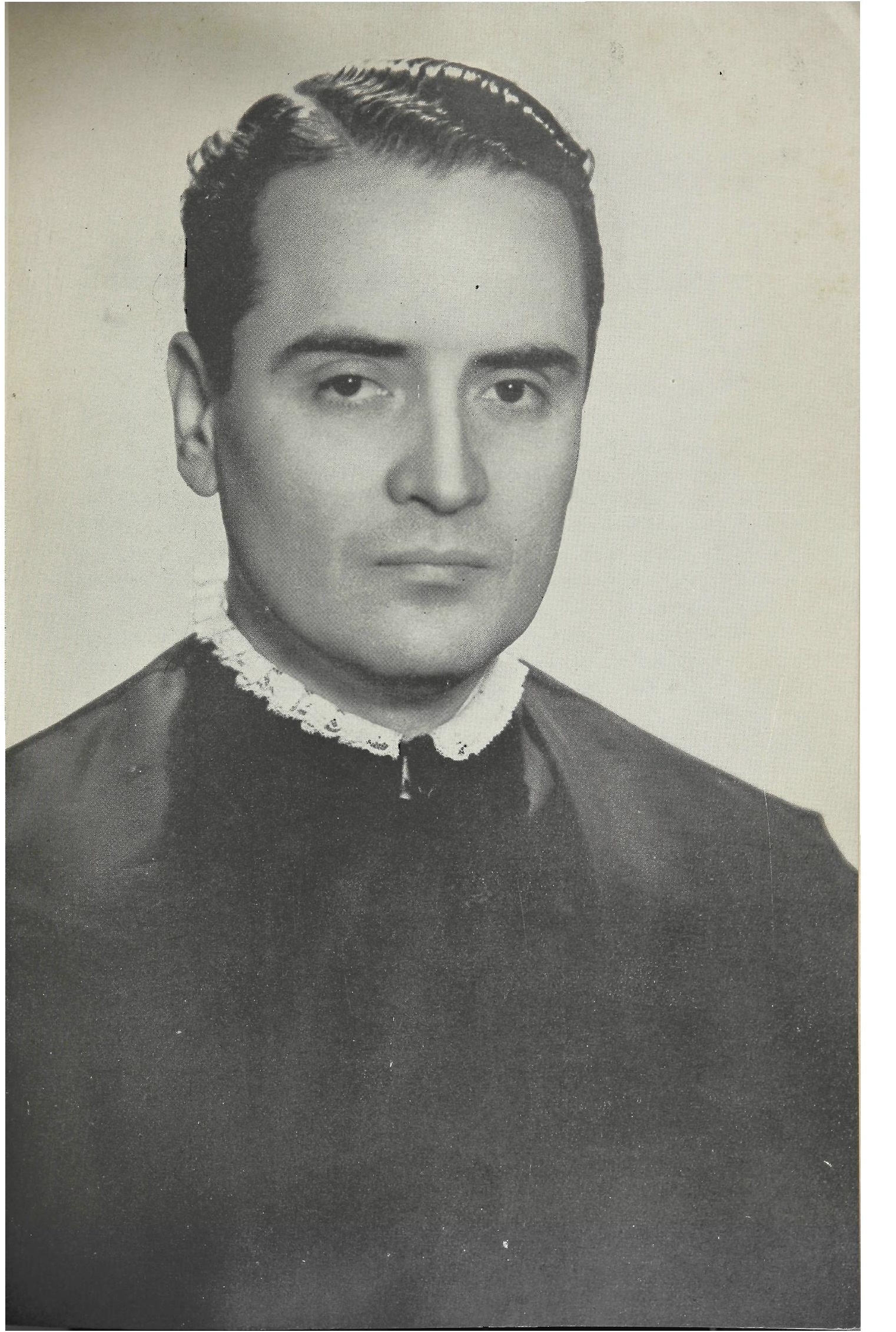




\section{Professor Goffredo da Silva Telles Junior}

(Catedrático de Introdução à Ciência do Direito)

O Professor Goffredo da Silva Telles Junior nasceu em 16 de maio de 1915.

E filho de Goffredo Teixeira da Silva Telles, advogado, poeta, membro da Academia Paulista de Letras, Prefeito de São Paulo em 1932; e de Dona Carolina Penteado da Silva Telles. Pelo lado paterno, é neto de Augusto Carlos da Silva Telles, que foi catedrático da Escola Politécnica, vereador e autor de vários trabalhos de engenharia e de urbanização; e de Dona Eugênia Teixeira Leite da Silva Telles, descendente do Barão de Vassouras. Pelo lado materno, é neto de Ignacio Leite Penteado, homem de idéias avançadas, fazendeiro em Araras e comissário de café em Santos; e de Olívia Guedes Penteado, filha dos Barões de Pirapitingui, mulher excepcional, que desempenhou papel relevante no desenvolvimento das artes em nosso país, e cuja lembrança perdura, até hoje, nos meios intelectuais do Brasil.

Goffredo da Silva Telles Junior fêz suas primeiras letras no Cours Hattmer de Paris, figurando seu nome, durante todo o tempo que alí estudou, no Tableau d'Honneur daquela conhecida instituição. Em São Paulo, fêz o curso primário e primeiro ano ginasial no Liceu Franco Brasileiro (atual Ginásio Pasteur); os outros quatro anos do curso secundário, fê-los no Ginásio de São Bento, por onde se formou em ciências e letras, no ano de 1932. Dúrante êsse período de estudos, publicou, sôbre os problemas da liberdade humana, do tempo e do espaço, diversos artigos nos jornais escolares, em que já se patenteavam os pendores 
naturais de seu espírito. Foi orador oficial do Grêmio Literário do Ginásio.

Durante a Revolução Constitucionalista, época durante a qual seu pai era Prefeito de São Paulo, serviu em Guaratinguetá, no Hospital de Sangue do Exército. Nessa ocasião tinha dezessete anos de idade.

Após exame vestibular, matriculou-se, em 1933, na Faculdade de Direito de São Paulo. Durante seus cinco anos acadêmicos, participou ativamente da polítića nacional e estadual. Em 1934, foi eleito suplente a deputado, à Assembléia Constituinte do Estado. Em 1934, inscreveu-se na Ordem dos Advogados, como solicitador acadêmico. Foi um dos fundadores da Associação Acadêmica Álvares de Azevedo e pertenceu à Academia de Letras da Faculdade. Na revista "O XI de Agôsto", publicou diversos artigos, entre os quais: "Orientação para o Estudo do Crime" e "Conceito de Direito Administrativo e de Ciência da Administração". Formou-se em 1937. O paraninfo de sua turma foi o Professor Jorge Americano, que pronunciou, durante a cerimônia da colação de grau, uma oração memorável. Merece menção a circunstância de ter sido a turma de 1937 a primeira a comparecer de beca à solenidade da formatura.

Em Maio e Junho de 1939, participou do coneurso para a conquista da cátedra de Direito Judiciário Penal. Foram seus concorrentes o livre docente Dr. Joaquim Canuto Mendes de Almeida e os promotores públicos Drs. João de Deus Cardoso de Mello e Vicente de Paula Vicente de Azevedo. Aprovado nas provas orais e escrita, não logrou, porém, classificação, por não ter obtido nota suficiente na prova de títulos. Saiu vencedor o Professor Joaquim Canuto Mendes de Almeida, que conquistou a cátedra; os outros dois concorrentes ficaram livres docentes.

Nessa ocasião, publicou seu primeiro livro: "Justiça e Jury no Estado Moderno", que lhe serviu de tese de concurso e que foi bem recebida pela crítica. 
Em Julho de 1939, casou-se com Dona Elza Xavier da Silva.

Exerceu ativamente a advocacia, principalmente a criminal, ocupando com frequência a tribuna do Júri. Em. Maio de 1940, foi contratado para exercer as funções de prof essor de Lógica do Colégio Universitário, anexo à Faculdade de Direito. E, em Setembro do mesmo ano, inscreveu-se para o concurso de livre docente da cadeira de Introdução à Ciência do Direito, na Faculdade de Direito da Universidade de São Paulo. Tal concurso se realizou em Março de 1941. Tendo defendido a tesse contida na monografia "A Definição do Direito", foi aprovado e, em 3 de Abril de 1942, nomeado livre docente da referida cadeira.

Representou a classe dos advogados no Primeiro Congresso Nacional do Ministério Público, realizado na cidade de São Paulo, durante o mes de Junho de 1942. Em Maio de 1943, foi admitido como membro efetivo do Instituto dos Advogados de São Paulo.

Em 15 de Outubro de 1942 e 17 de Fevereiro de 1943, o Professor Goffredo sofreu dois rudes golpes: perdeu, primeiro, seu filhinho de dois anos de idade e, depois, perdeu sua espôsa, que fôra sua companheira e colaboradora dedicada.

A partir de Maio de 1944, regeu, em diversos períodos, a cadeira de que era livre docente. Regeu, também, nesse mesmo ano, por convocação do catedrático, a cadeira de Direito Internacional Público. Foi professor de História Geral no Colégio do Estado. Na Faculdađe de Ciências Econômicas, anexa à Escola de Comércio Álvares Penteado, lecionou Direito Internacional Público e História das Doutrinas Políticas.

Em Outubro de 1944, foi nomeado membro do Conselho Penitenciário do Estado.

Em 2 de Dezembro de 1945, foi eleito deputado federal constituinte, pelo Partido de Representação Popular, sendo que a votação por êle obtida, foi a segunda em número 
de votos, entre as votações recebidas pelos candidatos a. deputado de todo o país. Na Assembléīa Constituinte e. na Câmara dos Deputados, esteve em atividade constante. No terreno espiritual, propôs e obteve a introdução da palavra "Deus" no preâmbulo da Constituição, e a entronização da imagem de Cristo no recinto do Plenário. Foi o primeiro deputado a dar resposta frontal aos discursos da bancada comunista. Combateu e obteve a retirada da emenda totalitária $n .^{\circ} 3.159$, que, se fôsse aprovada, deturparia o sentido democrático da Constĩtuição. No terreno das realizações práticas, batalhou pela implantação de um. sistema racional de discriminação de rendas, tendo escrito, sôbre o assunto, um longo trabalho, que figura nos Anais da Constituinte, e que se intitula: "O Sistema Brasileiro de Discriminação de Rendas". Foi um ardoroso defensor da causa municipalista. Tratou demoradamente dos problemas nacionais do algodão, do fio de seda, da brucelose. Combateu o primitivo tratado sôbre o Instituto Internacional da Hiléa Amazônica, que foi depois alterado. Alertou a opinião pública sôbre os abusos que estavam sendo praticados com nossos minérios preciosos e nossas areias monazíticas. Apresentou um projeto mandando incorporar os abonos aos salários dos trabalhadores, e um substitutivo, com longa justificação, ao projeto que reorganizava a Polícia Militar. Terminado seu mandato, em 1950, recusouse a pleitear nova eleição, e voltou para a Faculdade de Direito, de onde estava afastado havia cinco anos.

Em 19 de Abril de 1947, casou-se com a escritôra e advogada Lygia de Azevedo Fagundes, que passou a se assinar Lygia Fagundes Telles, e que fôra sua aluna em 1944.

Em 1949, publicou seu "Tratado da Consequência", que: é um curso de introdução à Filosofia e de Lógica formal.

A partir de $1 .^{\circ}$ de Março de 1951, regeu a cadeira de Introdução à Ciência do Direito, da qual o respectivo catedrático, o eminente Professor Spencer Vampré, estava afastado por motivo de moléstia. 
A convite do Centro Acadêmico XI de Agôsto, ministrou, na Faculdade de Direito, durante o segundo semestre de 1952, um curso livre de extensão cultural, sôbre a "Gênese da Norma Jurídica".

Em Outubro de 1953 , apresentando uma monografia em dois volumes, intitulada "A Criação do Direito", inscreveuse entre os candidatos ao concurso para a conquista da cátedra de que era livre docente. Seus concorrentes foram os bacharéis Alberto Moniz da Rocha Barros, Berto Antonio Condé, João Rodrigues de Mereje e Luís Silveira Melo. A Comissão examinadora ficou constituida pelos Professôres Doutores José Carlos de Ataliba Nogueira e Cândido Mota Filho, da Faculàade de Direito de São Paulo; Arnoldo Medeiros da Fonseca e Hélio Bastos Tornaghi, da Faculdade Nacional de Direito; e Darci Azambuja, da Faculdade de Direito da Universidade de Pôrto Alegre. As provas se realizaram entre 5 e 14, de junho de 1954. O Professor Goffredo da Silva Telles Junior foi aprovado em primeiro lugar, com a média 9,10. O bacharel Alberto Moniz da Rocha Barros conquistou a livre docência. Este concurso foi o primeiro, realizado na Faculdade de Direito da Universidade de São Paulo, para o provimento da catedra de Introdução à Ciência do Direito.

O novo catedrático tomou posse de sua cadeira na data evocativa de 11 de Agôsto de 1954, em sessão solene, realizada no salão nobre da Faculdade de Direito, peranie tôda a Congregação e grande assistência, estando presentes os juristas estrangeiros que participavam, em São Paulo, do Congresso Internacional de Direito Social. Foi saudado pelo Professor Dr. Braz de Souza Arruda, Diretor da Faculdade, e pelo Professor Dr. José Soares de Melo. Agradecendo, o Professor Goffredo da Silva Telles Junior pronunciou, de improviso, um longo discurso sôbre a missão do professor. Este discurso, que foi integralmente gravado, será publicado no próximo número desta Revista. 